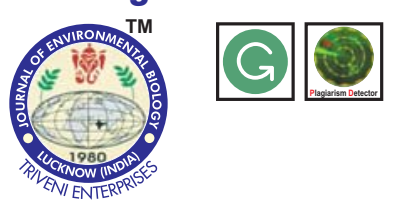

\title{
Rapid identification of endophytic fungi of sugarcane (Saccharum spp. hybrid) using PCR-RFLP of rDNA
}
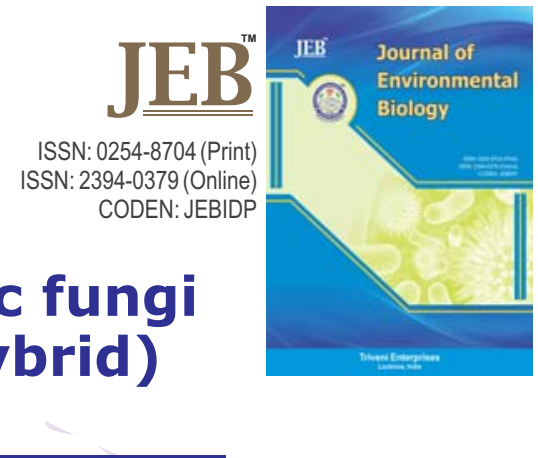

Authors Info

Sangeeta Srivastava ${ }^{1 *}$, Prashant Shekhar Gupta', Sunita Lal ${ }^{1}$ and O.K. Sinha ${ }^{2}$

'Division of Crop Improvement, ICAR-Indian Institute of Sugarcane Research, Lucknow-226 002, India

${ }^{2}$ AICRP(S), ICAR-Indian Institute of Sugarcane Research,

Lucknow- 226 002, India

${ }^{*}$ Corresponding Author Email : sangeeta_iisr@yahoo.co.in

Key words

Banding pattern,

Endophytic fungi,

Internal transcribed spacer,

PCR-RFLP assay, ribosomal DNA

Publication Info

Paper received : 03.12 .2015

Revised received: 03.03.2016

Accepted:04.05.2016

\section{Abstract}

Aim : Restriction fragment length polymorphism analysis of PCR-amplified internal transcribed spacer (ITS) regions of rDNA is a cheap and convenient molecular tool used in fungal taxonomy. This tool has been used for rapid identification of the endophytic fungi of sugarcane belonging to different genera for their further potential utilization.

Methodology : Eight isolates belonging to three endophytic fungi viz. Colletotrichum falcatum, Fusarium moniliforme and Trichoderma viride isolated from sugarcane plant were used for differentiation using PCR-RFLP pattern of rDNA. For this, the ITS1-5.8SITS2 region of rDNA was amplified with the help of universal primers and the PCR products were digested with various restriction enzymes.

Results : The size variation of amplified products ranged from $637 \mathrm{bp}$ (C. falcatum isolates), $592-614$ bp ( $F$. moniliforme isolates) to $631-698 \mathrm{bp}$ (T.viride isolates). Five restriction enzymes viz. Alu I, EcoR I, Bam H I, MSe I and Smal used for PCRRFLP of ITS fragments yielded a total of 54 bands that were arranged in three RFLP patterns.

Interpretation : Banding pattern obtained with the combination of Alu I and Mse I enzymes presented the best profile to identify the endophytic fungi and allowed distinction at molecular level. This reflected the potential of PCR-ITS-RFLP using a combination of restriction endonucleases as a rapid and convenient differentiation tool to distinguish these endophytic fungi.

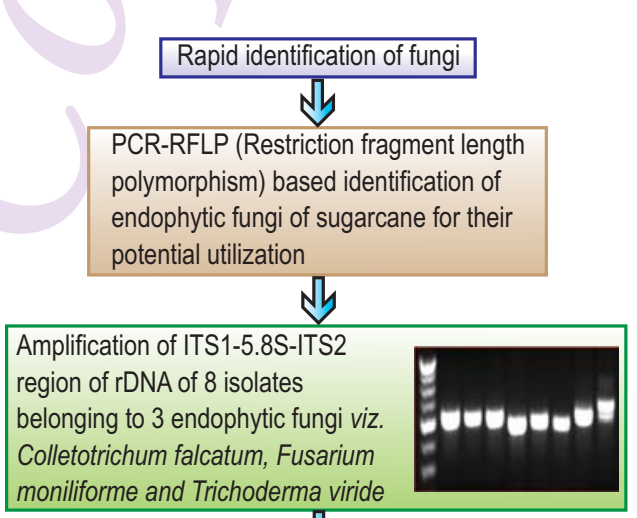

Nh

Restriction digestion of PCR amplicons with five restriction endonucleases viz. Alu I, EcoR I, Bam H I, Mse I and Sma I

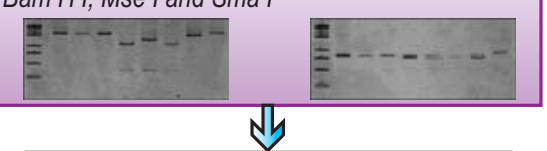

A total of 54 PCR-RFLP bands obtained were arranged in three RFLP patterns viz. I, II and III

Combination of Alu I and Mse I enzymes presented the best profile to identify the endophytic fungi

$\sqrt{5}$

PCR-ITS-RFLP using a combination of restriction endonucleases is a potential tool for rapid identification of fungal species 


\section{Introduction}

Endophytes commonly refer to a group of fungi that exist asymptomatically inside the living plant tissues for complete or part of their life cycle without causing any visible symptoms of their presence (Sánchez Márquez et al., 2008). They inhabit in various tissues, seeds, roots, stems and leaves (Johri, 2006). Their occurrence on various host plants suggests that fungal endophytes are ubiquitous in plant species (Hyde and Soytong, 2008, Sánchez Márquez et al., 2008; Zhang et al., 2006). Sugarcane (Saccharum spp.) is an important cash crop of India, primarily used for the production of sugar as well as biofuel alcohol. The association of microbial communities with sugarcane and their influence on bio-productivity is a concern of investigation. Various endophytic fungi belonging to different genera have been isolated from sugarcane cropping system (Fávaro et al., 2012; Stuart et al., 2010). Of these, Colletotrichum falcatum, Fusarium moniliforme and Trichoderma viride are the three important endophytic fungi of sugarcane. Their isolates have been identified based on cultural and morphological features. It is important to further identify these endophytic fungi for their potential utilization in growth promotion and disease resistance activities using molecular techniques.

Identification of fungi is traditionally done based on morphological characters (such as of conidial anatomy and appressoria shape), pathogenicity tests and physiological and biochemical approaches (Zhang et al., 2006). However, special care is required for differentiating closely related or morphologically identical fungal genera at species and subspecies level, because the morphological characteristics of some fungi may vary depending on the culture media and conditions as these factors substantially affect their vegetative and sexual compatibility (Hyde and Soytong, 2008; Zhang et al., 2006). Nowadays, the most precise tools for differentiating two closely related species/genera are molecular biology-based tools, such as AP-PCR (arbitrarily primed- polymerase chain reaction) or RAPD (Randomly amplified polymorphic DNA), mt DNA RFLPs (mitochondrial DNA restriction fragment length polymorphisms), and rDNA (ribosomal DNA) restriction analysis (Morelock et al., 2002; Promputtha et al., 2005). These approaches have greatly facilitated detection of array of pathogens like viruses, bacteria, phytoplasmas and fungi (Martínez-Culebras et al., 2002; Moritz et al., 2000). Among the molecular methods, those which are based on the nucleotide variability of ITS (internal transcribed spacer) region, have been shown to be useful for the taxonomic characterization of many fungal species because the ITS regions of nuclear rDNA consisting of two non-coding variable regions of ITS1 flanked by the $18 \mathrm{~S}$ and the $5.8 \mathrm{~S}$ subunits and ITS2 flanked by the $5.8 \mathrm{~S}$ and the $28 \mathrm{~S}$ subunits are often highly variable between isolates of the same species of fungus and, are therefore, the best tools for the phylogenetic analysis and differentiation of closely related fungal taxa (Salazar et al., 1999).
RFLP (Restriction fragment length polymorphism) analysis of the PCR-amplified internal transcribed spacer (ITS) regions of rDNA has further facilitated microbial taxonomy e.g. identification of strains of Penicillium subgenus Bivertilillium (Dupont et al., 2006), differentiation of $P$. expansum among fungal species (Garcia et al., 2006), grouping of $A$. flavus isolates infecting maize (Mohankumar et al., 2010) or bacterial diversity analysis of a municipal sewage treatment plant (Devi and Ramya, 2015). In the present study we developed and evaluated a PCR-RFLP assay of rDNA for rapid and easy identification and differentiation of endophytic fungi of sugarcane without any immediate need of sequencing.

\section{Materials and Methods}

Preparation of total genomic DNA : A total of 8 isolates of three endophytic fungi belonging to Colletotrichum falcatum (isolates Cf 07, Cf 08 and Cf 09), Fusarium moniliforme (isolates Fm 01, $\mathrm{Fm} 02$ and $\mathrm{Fm} \mathrm{03}$ ) and Trichoderma viride (isolates Tv 01 and Tv 02) were selected for their molecular identification using PCRRFLP. Isolation of these isolates was done from leaf and stem of sugarcane on potato dextrose agar medium (PDA composition: potato $250 \mathrm{~g}$, dextrose $20 \mathrm{~g}$ and agar $20 \mathrm{~g}$ per liter of water). The isolates were maintained in the laboratory at $20^{\circ} \mathrm{C}$. About $1 \mathrm{gm}$ of fungal mycelia was harvested with the help of a sterilized stainless steel spatula from actively growing cultures in PDA plates and ground in a pestle and mortar by adding adequate liquid nitrogen. Total genomic DNA was extracted using a slightly modified CTAB extraction protocol (Srivastava and Gupta, 2001). Isolated DNA was purified using RNAse and pellets were dissolved in $1 \mathrm{X}$ TE buffer. The purified DNA was visualized in $0.8 \%$ agarose gel stained with ethidium bromide to check its purity and to estimate its quantity. Uniform concentration of $5 \mathrm{ng} /$ $\mu$ l was standardized for the polymerase chain reaction. DNA was kept at $4{ }^{\circ} \mathrm{C}$ until further use and then stored at $-20^{\circ} \mathrm{C}$ in deep freezer.

Amplification of ITS region : The universal oligonucleotide primers ITS-4 (5'- TCC TCC GCT TAT TGA TAT GC -3') and ITS-5 (5'- GGAAGTAAAAGT CGTAACAAG G -3') were used (White et al., 1990) to amplify a nuclear rDNA gene fragment containing ITS1, ITS2 and the 5.8S rRNA gene by PCR using gDNA as template. The PCR amplification reactions were performed in a total volume of $50 \mu$ l. Each reaction mixture contained 10 to 100 ng of template DNA, $2 \mathrm{mM} \mathrm{MgCl}_{2}, 20 \mathrm{pmol}$ of each primer, $200 \mathrm{mM}$ of each dNTP and $2 \mathrm{U}$ of DNA polymerase (Bangalore Genei, Bangalore) in a PCR buffer containing $75 \mathrm{mM}$ Tris $\mathrm{HCl}(\mathrm{pH} 9.0)$, $50 \mathrm{mM} \mathrm{KCl}, 20 \mathrm{mM}\left(\mathrm{NH}_{4}\right)_{2} \mathrm{SO}_{4}$ and $0.001 \%$ BSA. The polymerase chain reaction was carried out in a PTC 200 Thermal Cycler (BioRad, U.S.A.) programmed to perform an initial denaturation step of $95^{\circ} \mathrm{C}$ for $5 \mathrm{~min}$, followed by 35 cycles consisting of $30 \mathrm{sec}$ at $95^{\circ} \mathrm{C}$ for denaturation, $30 \mathrm{~s}$ at $55^{\circ} \mathrm{C}$ for annealing and $1 \mathrm{~min}$ at $72^{\circ} \mathrm{C}$ for extension with 10 min elongation at $72^{\circ} \mathrm{C}$ followed by cooling at $4{ }^{\circ} \mathrm{C}$ for $15 \mathrm{~min}$. PCR products were resolved on a $2 \%$ 
Table 1 : Restriction profile of ITS regions of ribosomal DNA of fungal strain with different endonucleases and size estimates (base pairs) for fragment patterns

\begin{tabular}{|c|c|c|c|c|c|c|c|}
\hline & \multirow[b]{2}{*}{ Amplicon } & \multicolumn{5}{|c|}{ Fragment length in base pair using restriction enzyme } & \multirow{2}{*}{$\begin{array}{l}\text { Restriction } \\
\text { profile type }\end{array}$} \\
\hline & & EcoRI & Smal & Alul & Mse I & Bam HI & \\
\hline Cf07 & $637 b p$ & $\begin{array}{l}327 \\
310\end{array}$ & $\begin{array}{l}526 \\
111\end{array}$ & 637 & $\begin{array}{l}210 \\
202 \\
180 \\
36 \\
9\end{array}$ & 637 & \\
\hline Cf08 & $637 b p$ & $\begin{array}{l}327 \\
310\end{array}$ & $\begin{array}{l}526 \\
111\end{array}$ & 637 & $\begin{array}{l}209 \\
202 \\
181 \\
9\end{array}$ & 637 & I \\
\hline Cf09 & $637 b p$ & $\begin{array}{l}327 \\
310\end{array}$ & $\begin{array}{l}526 \\
111\end{array}$ & 637 & $\begin{array}{l}211 \\
202 \\
179 \\
36 \\
9\end{array}$ & 637 & \\
\hline Fm 01 & $592 \mathrm{bp}$ & $\begin{array}{l}304 \\
288\end{array}$ & 592 & $\begin{array}{l}422 \\
139 \\
31\end{array}$ & 592 & 592 & \\
\hline Fm 02 & $614 b p$ & $\begin{array}{l}304 \\
288\end{array}$ & $\begin{array}{l}362 \\
252\end{array}$ & $\begin{array}{l}475 \\
139\end{array}$ & 614 & 614 & II \\
\hline Fm 03 & $592 b p$ & $\begin{array}{l}304 \\
288\end{array}$ & 592 & $\begin{array}{l}422 \\
139 \\
31\end{array}$ & 592 & 592 & \\
\hline Tv 01 & $631 \mathrm{bp}$ & $\begin{array}{l}335 \\
296\end{array}$ & 631 & 631 & 631 & 631 & III \\
\hline Tv02 & $698 \mathrm{bp}$ & $\begin{array}{l}358 \\
340\end{array}$ & 698 & 698 & 698 & $\begin{array}{l}569 \\
129\end{array}$ & \\
\hline
\end{tabular}

agarose gel containing $1 \mathrm{mg} \mathrm{ml}^{-1}$ ethidium bromide in tris-acetate buffer $(0.04 \mathrm{M}$ tris-acetate, $0.001 \mathrm{M}$ EDTA, pH 8.0) at $80 \mathrm{~V}$ for 45 min in BioRad SubCell GT electrophoresis unit. The amplified DNA fragments were visualized by UV transillumination and analyzed using Alphalmager ${ }^{\mathrm{TM}}$ Gel Documentation System (Protein Simple, USA).

Cleaning-up and restriction of PCR products : The PCR products were eluted from the gel and purified using the Ultrafree DA Gel Extraction Kit (Millipore, USA) following the manufacturer's instructions. Purified PCR products of each isolate were digested with the restriction enzymes Alu I, EcoRl, Bam HI, MSe I and Sma I (Bangalore Genei, Bangalore) in a total volume of $20 \mu$ containing approximately $200 \mathrm{ng}$ amplified DNA, $10 \mathrm{U}$ of enzyme in final concentration of $1 \mathrm{X}$ digestion buffer. Incubation was done at $37^{\circ} \mathrm{C}$ for $16 \mathrm{hrs}$ in the thermal cycler. Restricted fragments were separated in 10\% Acrylamidebisacrylamide gel with $0.5 \mathrm{X}$ TBE buffer in vertical electrophoresis unit of Bio Rad. Electrophoresed gels were silver stained and amplified bands were visualized and documented in Alphalmager $^{\mathrm{TM}}$ Gel documentation system (Protein Simple, USA). Size of fragments was estimated by doing comparison with a standard 100 bp DNAladder (Bangalore Genei, Bangalore).

\section{Results and Discussion}

PCR- RFLP identification : The ITS4 and ITS5 primer pair described by White et al. (1990) was used in this study to amplify the ribosomal DNA region from eight isolates of three endophytic fungi of sugarcane viz. C. falcatum, F. moniliforme and $T$. viride. The amplified PCR products belonged to two non-coding regions of ITS1 and ITS2, and the 5.8S rRNA gene (ITS1-5.8S-ITS2). There was no intraspecific difference in size of amplified PCR products in C. falcatum isolates and F. moniliforme isolates Fm 01 and $\mathrm{Fm} 03$, but it differed between the genera and among rest of

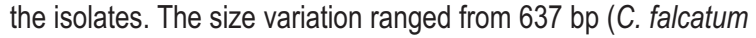
isolates), 592-614 bp (F. moniliforme isolates) to 631-698 bp ( $T$. viride isolates) as presented in Fig. 1. Such size variations are not unexpected in PCR using ITS region primers. Gomes et al. (2002) found extensive length polymorphism in ITS region (from 560 to $750 \mathrm{bp}$ ) in 26 isolates of 8 ectomycorrhizal fungi genera. Highly variable lengths of ITS1/ITS4 amplified fragments were observed in different fungal genera ranging from as small as $380 \mathrm{bp}$ to up to 880 bp (Korabecna (2007) and 539 to 626 bp (Diguta et al., 2011). 
Restriction digestion of ITS amplified fragments was done for further detection of the variability among these endophytic fungal isolates. Five restriction enzymes consisting of 4-bp and 6bp cutter enzymes viz. Alu I, EcoR I, Bam H I, MSe I and Sma I were used, which yielded a total of 54 bands. For some enzymes, length of restricted fragment was same, whereas, some enzymes did not cut all the genera. Size similarity of restricted fragments may occur due to sequence similarity of ITS region being cut. Nikolcheva et al. (2003) also found conserved restriction sites for Msp I and Rsa I while using different restriction enzymes for terminal restriction fragment length polymorphism (T-RFLP) analysis of aquatic hyphomycete community. In such cases, selection of appropriate restriction enzymes becomes crucial

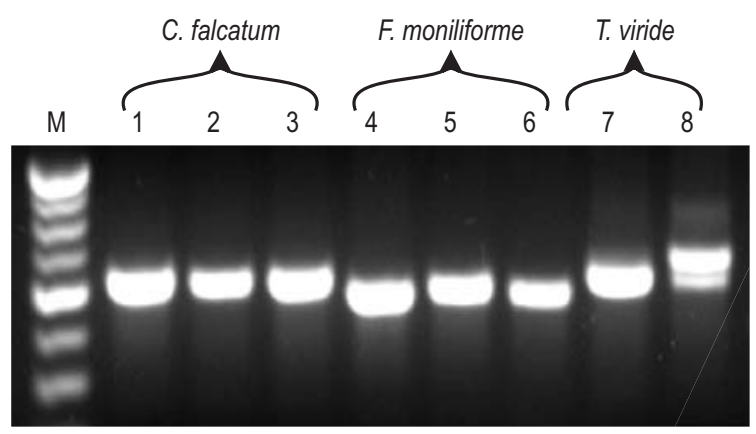

Fig. 1 : Agarose gel electrophoresis of PCR amplicon of different fungal isolates using $r$ DNA gene sequence as primers ITS 4 and ITS 5. (Lane 1 to 9: $\mathrm{M}-100 \mathrm{bp}$ DNA ladder of Bangalore Genei; $1,2,3=\mathrm{Cf} 07, \mathrm{Cf} 08$, Cf $09 ; 4,5,6=\mathrm{Fm} \mathrm{01}, \mathrm{Fm} \mathrm{02}, \mathrm{Fm} 03$ and $7,8=$ Tv 01, Tv 02 respectively)

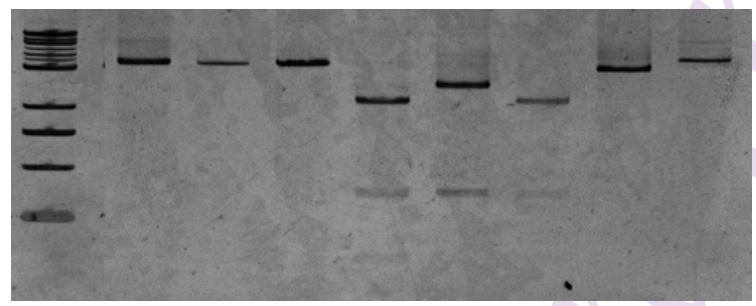

(a)

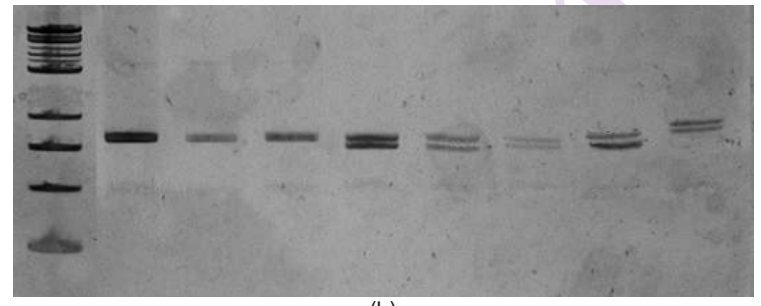

(b)

Fig. 2 : Silver stained PAGE of ribosomal DNA restriction profile of different fungal isolates after digestion with the restriction endonucleases a.RFLP profile with Alu I; b. RFLP profile with Eco R I; (Lane 1 to 9: M 100bp DNA ladder of Bangalore Genei; 1, 2, 3 = Cf 07, Cf 08, Cf 09; 4, 5, 6 $=\mathrm{Fm} \mathrm{01,} \mathrm{Fm} \mathrm{02,} \mathrm{Fm} 03$ and $7,8=\operatorname{Tv} 01$, Tv 02 respectively) which can be done by hit and try approach. Nikolcheva et al. (2003) further found that the restriction enzyme Dde I gave the most variable RFLP pattern in the pure aquatic hyphomycete controls followed by the enzymes Cfo I, Hae III, Hinf I. In our study also, different restriction enzymes showed different cutting patterns with different endophytic fungi. e.g. Alu / cut only the three Fusarium isolates and Bam HI did not cut any isolate except Trichoderma isolate Tv 02. Similarly Sma I did not cut two Fusarium isolates- Fm 01 and Fm 03, and Trichoderma isolates Tv 01 and Tv 02. For restriction enzyme Mse I, there was no cutting site in the genus Fusarium and Trichoderma (isolate Tv 02). Mergulhão et al. (2008) could also not find any restriction sites for the enzyme Alu I, however, they observed that the restriction patterns of $\mathrm{Hinf} I$ and $\mathrm{Mbo} /$ in combination with other enzymes were able to differentiate four AMF species. In the present study also, the combination of restriction enzymes showed polymorphism in size of restricted fragments, based on which three RFLP patterns viz. RFLP patterns I, II and III were discerned which could differentiate these endophytic fungi (Table 1). The representative RFLP patterns with restriction enzymes Alu land Eco R/are depicted in Fig. 2 a, b.

The RFLP pattern I was generated by the three Colletotrichum isolates. The amplified 5.8S-ITS rDNA region of these isolates had one restriction site each for Eco RI and Sma I and four sites for Mse I. The restriction enzyme Alu I and Bam HI yielded only a single fragment of same size as the amplified region. The RFLP pattern II was generated by the three isolates of Fusarium, where, amplified ITS region had one restriction site for $E c o R$ I in all the three isolates. Digestion with Alu I revealed two restriction sites in isolates $\mathrm{Fm} 01$ and $\mathrm{Fm} 03$ and one restriction site in Fm 02. For restriction enzymes Bam H I and Mse I, there was no cutting site in Fusarium. The RFLP pattern III was represented by the two isolates of Trichoderma, where Eco $R$ I had one restriction site in amplified products. Restriction enzymes Sma I, Alu I and Mse I did not cut the amplified fragment. The restriction enzyme Bam H I cut only Tv 02 isolate.

Analysis of RFLP pattern of ITS1-5.8S-ITS2 PCR amplicons with restriction endonucleases: Amplification of 5.8S rRNA gene, the conserved coding region along with two non-coding and variable flanking regions ITS1 and ITS2, generally show low intraspecific variability but high interspecific polymorphism and are thus suitable for identification of different fungi (Salazar et al., 1999). ITS length variations (between 500 to 550 bp) and, presence of SNPs (single nucleotide polymorphisms) and INDELS (insertions /deletions) were observed in ITS1 and ITS2 regions of ribosomal DNA, encompassing the 5.8S rRNA gene nuclear ribosomal DNA of ten species of Pestalotiopsis (Gehlot et al., 2012). In the present study, the use of PCR primers ITS4 I ITS5 resulted in amplification of single fragment in all isolates of endophytic fungi but its size varied among the isolates from 592 to 698 bp (637 bp in C. falcatum, 592 - 614 bp in F. moniliforme and 
631 - 698 bp in Trichoderma viridae). The analysis of the restriction profile (RFLP pattern) of these ITS fragments resulted in identification of two restriction endonucleases Alu I and MSe I that could reliably be used for rapid and easy identification of the three endophytic fungi in sugarcane. The PCR-RFLP using Alu I and $M S e I$, revealed 2 to 5 fragments per restriction enzyme in each fungal isolate, with three distinct restriction patterns overall (Table 1). According to restriction profile, there were one to two restriction sites for Alu I in F. moniliforme that cleaved the PCR products of isolates Fm 01 and $\mathrm{Fm} 03$ into 3 fragments of $422 \mathrm{bp}$, $139 \mathrm{bp}$, and $31 \mathrm{bp}$ while two products of $475 \mathrm{bp}$ and $139 \mathrm{bp}$ were obtained in isolate Fm 02 (Fig. 2a). There were 4 restriction sites in Colletotrichum isolates for MSe I that cleaved the PCR products into 5 fragments of 210,202, 180, 36 and 9 bp each. On the other hand, there was no restriction site for Alu I and MSe I in the PCR products of Trichoderma isolates. Digestion of the PCR products with endonucleases Eco $R$ / showed one cutting site in the ITS region of all the endophytic fungi resulting in two bands of nearly 327 bp and 310 bp in Colletotrichum, 304 bp and 288 bp in Fusarium and 358 bp, 340 bp, and 296 bp in Trichoderma (Fig. $2 b$ ). For the endonuclease $\mathrm{Bam} \mathrm{HI}$, there was one cleavage site in Trichoderma strain Tv 02 resulting in two bands (569 bp and $129 \mathrm{bp}$ ), however no cutting sites in remaining endophytic fungi were observed. The digestion fragments ranging from 31 to 422 bp in Alu I and 9 to 211 bp in Mse I were differentiated between the three endophytes (Fig. 2a and 2b). No restriction sites were found in C. falcatum and T. viride digested with Alu I (Table 1). Consequently, no variation between the $C$. falcatum and $T$. viride was detected with this enzyme. On the other hand, the combination of the restriction patterns of enzymes Alu I, MSe I, EcoR I and Sma I allowed the molecular distinction of all species, mainly with the profiles obtained with endonuclease MSe I.

The detailed comparison of the restriction profile of the ITS fragments with Alu I and MSe / proved that the size profiling of the PCR amplified bands after restriction using endonucleases Alu I and MSe I, is extremely useful as one of the rapid tools for identification and monitoring of endophytic fungal species. Using a combination of the restriction patterns of two or more enzymes to allow the molecular distinction is not uncommon. Lee et al. (2003) used combinations of three restriction enzymes, Hinfl, Alu I and AsuC21 for RFLP of partial small subunit of ribosomal DNA of AMF (Arbuscular mycorrhizal fungi) and plant pathogenic species of Fusarium, and found that distinct polymorphism was achieved only with AsuC21. A similar type of observation was made by Mergulhao et al. (2008), while doing PCR-RFLP of ITS region of AMF. They observed that the restriction enzymes Hinf I and Mbo I were able to differentiate four AMF species, whereas, no restriction sites were obtained for the restriction enzyme Alu I. Similarly, species of Phaeoacremonium were identified by restriction digestion pattern of ITS1F/ITS4 amplified PCRamplicons using restriction enzymes BssK I, EcoO109 I, and Hha I (Aroca and Raposo, 2007). Viaud et al. (2000) also substantiated the fact that the PCR-RFLP of ITS region could be used as an efficient molecular tool to distinguish a large number of fungal samples without going for sequence analysis.

Interpretation of the restriction pattern obtained is generally rapid, reliable and cheaper as compared to morphological traits and no need to go for the conventional sequencing of PCR products; hence the process can be adopted on a large scale in a short time. The present study also proved it to be a rapid and convenient tool for differentiation of endophytic fungi of sugarcane using PCR-RFLP with only three steps to perform: (1) to amplify the ITS fragment with the universal ITS primers (2) to digest PCR products with suitable restriction enzymes and (3) to run the digested product on vertical PAGE to identify the samples based on their restriction profiles. The method excluded the influence of artificial factors and thus improved the validity of identification greatly and hence has a great potential for utilization as a tool to differentiate the major endophytic fungi in sugarcane with high phylogenetic affinity.

\section{Acknowledgment}

The authors are highly grateful to the Director, ICAR-IISR, Lucknow, for providing necessary facilities to carry out the experiments.

\section{References}

Aroca, A. and R. Raposo: PCR-based strategy to detect and identify species of Phaeoacremonium causing grapevine diseases. Appl. Environ. Microbiol., 73, 2911-2918 (2007).

Devi, S.G. and M. Ramya: PCR-RFLP based bacterial diversity analysis of a municipal sewage treatment plant. J. Environ. Biol., 36, 11131118 (2015).

Diguta, C.F., B. Vincent, M. Guilloux-Benatier, H. Alexandre and S. Rousseaux: PCR ITS-RFLP: A useful method for identifyting filamentous fungi isolates on grapes. Food Microbiol., 28, 11451154 (2011).

Dupont, J., B. Dennetiere, C. Jacquet and M.F. Roquebert: PCR-RFLP of ITS rDNA for the rapid identification of Penicillium subgenus Biverticillium species. Revi. Iberoame. Micol., 26, 145-150 (2006).

Fávaro, L.C., F.L. Sebastianes and W.L. Araújo: Epicoccum nigrum P16, a sugarcane endophyte, produces antifungal compounds and induces root growth. PLOS ONE, 7, e36826 (2012).

Garcia, C., S. La Guerche, B. Mouhamadou, C. Férandon, J. Labarère, D. Blancard, P. Darriet and G. Barroso: A CAPS test allowing a rapid distinction of Penicillium expansum among fungal species collected on grape berries, inferred from the sequence and secondary structure of the mitochondrial SSU-rRNA. Inter. J. Food Microbiol., 111, 183-190 (2006).

Gehlot, P., S.K. Singh and R. Pathak: Morphometric and molecular characterization of fungus Pestalotiopsis using nuclear ribosomal DNAanalysis. J. Environ. Biol., 33, 897-901 (2012).

Gomes, E.A., M.C.M. Kasuya, E.G. de Barros, A.C. Borges and E.F. Araújo: Polymorphism in the internal transcribed spacer (ITS) of the ribosomal DNA of 26 isolates of ectomycorrhizal fungi. Genet. Molec. Biol., 25, 477-483 (2002). 
Hyde, K.D. and K. Soytong: The fungal endophyte dilemma. Fun. Diver., 33, 163-173 (2008).

Johri, B.N.: Endophytes to the rescue of plants. Curr. Sci., 90, 1315-1316 (2006).

Korabecna, M., V. Liska and K. Fajfrlik: Primers ITS1, ITS2 and ITS4 detect the intraspecies variability in the internal transcribed spacers and $5.8 \mathrm{~S}$ rRNA gene region in clinical isolates of fungi. Folia Microbiol., 48, 233-238 (2003).

Lee, J.K., M.S. Tae.,A.H. Eom and S.S. Lee: Restriction analyses of PCR amplified partial SSU ribosomal DNA to distinguish arbuscular mycorrhizal fungi from other fungi colonizing plant roots. Mycobiol., 31, 68-73 (2003).

Martínez-Culebras P.V., E. Barrio, M.B. Suarez-Fernandez, M.D. GarciaLopez and A. Querol: RAPD analysis of Colletotrichum species isolated from strawberry and the design of specific primer for the identification of C. fragariae. J. Phytopath. 150, 680-686 (2002).

Mergulhao, A.C.E.S., M. Vanusa da Silva, M.V.B. Figueiredo, H.A. Burity and L.C. Maia: Characterization and identification of arbuscular mycorrhizal fungi species by PCR/RFLP analysis of the rDNA internal transcribed spacer (ITS). Ann. Microbiol., 58, 341-344 (2008).

Mohankumar, M., A. Vijayasamundeeswari, M. Karthikeyan, S. Mathiyazhagan, V. Paranidharan and R. Velazhahan: Analysis of molecular variability among isolates of Aspergillus flavus by PCRRFLP of the ITS regions of rDNA. J. Plant Prot. Res., 50, 446-451, (2010).

Morelock, T.E., B. Liu, L.A. Wasilwa and J.C. Correll: Comparison of Colletotrichum orbiculare and several allied Colletotrichum spp. for mtDNA RFLPs, intron RFLP sequence variation, vegetative compatibility, and host specificity. Phytopathology, 97, 1305-1314 (2007).

Moritz, G., C. Delker, M. Paulsen, L.A. Mound and W. Burgermeister:
Modern methods for identification of Thysanoptera. EPPO Bull., 30, 591-593 (2000).

Nikolcheva, L.G., A.M. Cockshutt and F. Bärlocher: Diversity of freshwater fungi on decaying leaves - comparing traditional and molecular approaches. Appl. Environ. Microbiol., 69, 2548-2554 (2003).

Promputtha, I., R. Jeewon, S. Lumyong, E.H.C. McKenzie and K.D. Hyde: Ribosomal DNA fingerprinting in the identification of non sporulating endophytes from Magnolia liliifera (Magnoliaceae). Fun. Diver., 20, 167-186 (2005).

Salazar, O., J.H.M. Schneider, M.C. Julian, J. Keijer and V. Rubio: Phylogenetic subgrouping of Rhizoctonia solani AG2 isolates based on ribosomal ITS sequences. Mycologia, 91, 459-467 (1999).

Sánchez Márquez, S., G.F. Bills and I. Zabalgogeazcoa: Diversity and structure of the fungal endophytic assemblages from two sympatric coastal grasses. Fun. Diver., 33, 87-100 (2008).

Srivastava, S. and P.S. Gupta: Microprep protocol for DNA isolation from sugarcane. Ind. J. Sugar. Technol., 16, 88-90 (2001).

Stuart, R.M., A.S. Romão, A.A. Pizzirani-Kleiner, J. Lúcio, A. Welington and L. Araújo: Culturable endophytic filamentous fungi from leaves of transgenic imidazolinone-tolerant sugarcane and its nontransgenic isolines. Archi. Microbiol., 192, 307-313 (2010).

Viaud, M., A. Pasquier and Y. Brygoo: Diversity of soil fungi studied by PCR-RFLP of ITS. Mycol. Res., 9, 1027-1032 (2000).

White, T.J., T. Bruns, S. Lee and J. Taylor: Amplification and direct sequencing of fungal ribosomal RNA genes for phyl ogenetics. In: PCR protocols: a guide to methods and applications (Eds.: M.A. Innis, D.H. Gelfand, J.J. Sninsky and T.J. White). Academic Press, New York, USA, pp. 315-322 (1990).

Zhang, H.W., Y.C. Song and R.X. Tan: Biology and chemistry of endophytes. Nat. Prod. Repo., 23, 753-771 (2006). 